\title{
Projetos criativos ecoformadores em pesquisas com intervenção: contribuições para uma educação complexa
}

\section{Resumo}

\author{
Marlene Zwierewicz* \\ Beatriz Alves de Oliveira** \\ Nadir Zimmer Telegen*** \\ Erenita Hoffmann ${ }^{* * * *}$
}

Superar práticas pedagógicas centradas na fragmentação do conhecimento para se aproximar de uma educação complexa demanda mudanças epistemológicas e metodológicas. Este artigo discute esse processo e apresenta fragmentos dos resultados de três pesquisas de mestrado que envolveram a metodologia dos Projetos Criativos Ecoformadores (PCE)

* Orcid: http://orcid.org/0000-0002-5840-1136. Grupo de Pesquisa em Complexidade, Ecoformação e Transdisciplinaridade - Gcet. Programa de Pós-Graduação Mestrado Profissional em Educação Básica - PPGEB. Universidade Alto Vale do Rio do Peixe - UNIARP. Caçador, Brasil. Rede Internacional de Escolas Criativas - RIEC. Barcelona, Espanha. marlenezwie@ yahoo.com.br

** Orcid: https://orcid.org/0000-0002-1171-5031.Centro Municipal de Educação Infantil Elmar Pereira Rosa. Rede Municipal de Ensino de Caçador. Caçador, Brasil. Programa de Pós-Graduação Mestrado Profissional em Educação Básica - PPGEB. Universidade Alto Vale do Rio do Peixe - UNIARP. Caçador, Brasil, beatrithe@hotmail.com

*** Orcid: hhttps://orcid.org/0000-0002-3921-7755. Escola Municipal de Ensino Fundamental Professora Cândida Bertotto Zucatti. Rede Municipal de Ensino de Macieira. Macieira, Brasil. Programa de Pós-Graduação Mestrado Profissional em Educação Básica - PPGEB. Universidade Alto Vale do Rio do Peixe - UNIARP. Caçador, Brasil, nadir_telegen@yahoo.com.br

**** Orcid: https://orcid.org/0000.00033-2584-3875. Escola Municipal de Educação Básica Gleidis Rodrigues. Rede Municipal de Ensino de Timbó Grande. Timbó Grande, Brasil. Programa de Pós-Graduação Mestrado Profissional em Educação Básica - PPGEB. Universidade Alto Vale do Rio do Peixe UNIARP. Caçador, Brasil. nitahoffmann01@hotmail.com 
para estimular ou ampliar essa transição em escolas de Educação Básica de três municípios catarinenses. Os resultados obtidos por meio de uma pesquisa bibliográfica e a priorização da abordagem qualitativa possibilitaram a identificação de dez indicadores definidos na pesquisa de Telegen (2009) a fim de avaliar a proximidade de diferentes projetos de ensino e de aprendizagem com a metodologia do PCE, além de possibilidades para a pertinência do ensino contextualizadas na pesquisa situadas na pesquisa de Hoffmann (2019) e, ainda, condições para o estímulo ao desenvolvimento integral compiladas na pesquisa de Oliveira (2020).

Palavras-chave: Educação complexa; Pertinência; Transdisciplinaridade; Ecoformação.

\section{Ecoforming creative projects in researches with intervention: contributions to a complex education}

\section{Abstract}

To overcome the pedagogical practices centered in knowledge fragmentation to approach a complex education demands epistemological and methodological changes. This article discusses this process and presents fragments results of three master's researches that involved the Ecoforming Creative Projects [Projetos Criativos Ecoformadores - PCE] methodology to stimulate or expand this transition in elementary schools in three municipalities in Santa Catarina. The results obtained through a bibliographic research and the qualitative approach prioritization enabled the identification of ten indicators defined in research by Telegen (2009), in order to assess the proximity of different teaching and learning projects with the PCE methodology; also the contextualized possibilities in research for the relevance of teaching in Hoffmann's research (2019); and, additionally, conditions for encouraging integral development found in Oliveira (2020).

Keywords: Complex Education; Relevance; Transdisciplinarity; Ecoforming.

\section{Proyectos creativos ecoformadores en investigaciones con intervención: contribuciones para una educación compleja}

\section{Resumen}

Superar las prácticas pedagógicas que se centran en la fragmentación del conocimiento, con el objetivo de aproximarse a una educación compleja, 
requiere transformaciones epistemológicas y metodológicas. Este artículo discute este proceso, presentando fragmentos de tres investigaciones de maestría que usaron la metodología de los Proyectos Creativos Ecoformadores (PCE), para estimular o ampliar esa transición en escuelas de Educación Básica de tres municipios de Santa Catarina, uno de los tres estados del sur de Brasil. Los resultados obtenidos por medio de una investigación bibliográfica permitieron reconocer diez indicadores definidos en la investigación de Telegen (2009), para evaluar la proximidad de diferentes proyectos de enseñanza y de aprendizaje con la metodología de los PCE; posibilidades para la pertinencia de la enseñanza contextualizadas en la investigación, mencionadas en el trabajo de Hoffmann (2019); y condiciones para estimular el desarrollo integral encontradas en Oliveira (2020).

Palabras clave: Educación compleja; Pertinencia; Transdisciplinariedad; Ecoformación.

\section{Introdução}

As demandas da realidade atual e as incertezas em relação ao futuro posicionam docentes da Educação Básica e do Ensino Superior diante de uma bifurcação epistemológica e metodológica: ou seguem os itinerários de sua atuação docente marcada pelo ensino colonizado e descontextualizado ou optam por uma atuação docente pautada pela religação dos saberes e desses em relação à realidade local e global.

A segunda opção se orienta pela superação "[...] de uma visão fragmentada, disjuntiva e separadora do ser humano em relação à natureza e à sociedade" (SÁ, 2019, p. 19). Seus pontos de referência caracterizam aquilo que Petraglia (2008, p. 35) nomeia como educação complexa, cujo papel é "[...] propiciar a reflexão e a ação de resgatar a nossa essência e a nossa humanidade, acenando com novas perspectivas de resistência, emancipação e felicidade".

Os docentes que optam por esse itinerário se afastam da escola desconectada da vida a fim de fortalecer instituições educacionais que valorizam o conhecimento pertinente. Ou seja, o conhecimento produzido pela racionalidade aberta e que contextualiza e concebe a multidimensionalidade humana, social e da natureza (SÁ, 2019). 
Por isso, sua proximidade com a pertinência do ensino, uma condição fortalecida na superação da visão educacional que coaduna não somente com a cisão entre tempo e história, mas também entre ciência e ser humano, acirrando "[...] o individualismo e, com ele, o isolamento do sujeito” (PETRAGLIA, 2008, p. 32). Esse processo requisita uma luta anticolonialista, justificada por Rivas Flores (2019) pela necessidade de superar a escola homogeneizadora de um pensamento técnico validado cientificamente, com orientação unidirecional e pautado em standards que se utilizam da segregação para excluir ao tratar como igual o que, na essência, é diferente.

Cavalcante, Aquino e Melo (2019, p. 100) reforçam que a descolonização é necessária para dialogar com todas as pessoas. Isso demanda escolas que em seus currículos, de modo igual, dialoguem com aqueles que, inexoravelmente, se encontram “ [...] fora do circuito de trabalho assalariado e da produção da mais-valia [...]”, o que significa rever o conhecimento 'clássico' como conteúdo privilegiado da escola.

Esse conhecimento, cientificamente validado, único e estandardizado, desconsidera uma necessidade histórica latente da espécie humana, que é a de viver, coletiva e colaborativamente, motivada por um bem comum. Ou seja, uma necessidade básica que Baumeister e Leary (1995) definem como 'pertencimento'.

Existe uma “[...] dimensão subjetiva que motiva o pertencer a um todo [...]" constituída pelo“[...] próprio sentimento de pertencimento, acionado de alguma forma pela necessidade já presente nesse todo que é buscado como objetivo-fim [...]". À medida em que se amplia esse todo, sua visibilidade e a abrangência do objeto-fim, bem como da motivação e da participação, “[...] entra-se na fronteira de comunidade e de sua relação com o todo social mais amplo definido pela sociedade" (SOUSA, 2010, p. 37).

Nessa relação entre pertencimento-comunidade-sociedade, o autor destaca que diferentes instituições, entre as quais as de ensino, constituem uma rede de socialização primária, com características históricas de comunidade-pertencimento. Essas instituições 
tornam "[...] visível um contato face a face e a relação de troca de valores [...]" configurando a identidade desde a diferença, apoiada por "[...] bases de territórios não só simbólicos, mas físicos [...]", gerando um sentimento de enraizamento. Nesse sentido, “[...] Só existe comunidade quando se expressa o pertencer a esse todo (SOUSA, 2010, p. 37).

Baumeister (2012) conclui que a necessidade de pertencimento tem influência sobre outras variáveis psicológicas e fisiológicas, além de registrar que a não satisfação dela é prejudicial ao indivíduo. Na mesma direção, Dewall e Baumeister (2006) afirmam que déficits no sentimento de pertencimento foram identificados como prejudiciais às habilidades de socialização, levando à ansiedade e ao isolamento social.

Gastal e Pilati (2016, p. 286), por sua vez, afirmam que "Apesar de ser definida como uma motivação comum a todos os seres humanos, existe variação na força e influência da necessidade de pertencimento na vida de cada indivíduo". Para esse argumento, eles têm como base os estudos de Leare e Kelly, publicados em 2009 , nos quais alegaram o fato de existirem pessoas que apresentam forte motivação para manter relações de aceitação e de pertencimento, direcionando maiores esforços para tal objetivo, enquanto outras apresentam uma motivação mais amena com o intuito de manter conexões sociais.

Independentemente da predisposição, não basta estar junto para se sentir pertencente. É preciso partilhar da experiência do outro, vivenciando uma atitude recíproca de interioridade (PAIVA, 2000), condição que é dificultada quando se prioriza, na escola, o currículo colonizado e descontextualizado e não se estimula o desenvolvimento integral.

Em relação ao desenvolvimento integral, observa-se uma ênfase em superar o estímulo exclusivo ao desenvolvimento cognitivo em vários documentos que regulamentam a educação brasileira, especialmente a Educação Infantil. Ao analisar a regulamentação, Felipus (2019) situou a ênfase atribuída em parte desses documentos conforme sistematizado na sequência: 
- Lei de Diretrizes e Bases da Educação Nacional - LDBEN 9394/96: faz referência ao desenvolvimento integral no art. 29, quando define que compete à Educação Infantil o desenvolvimento integral da criança até seis anos de idade

- Referencial Curricular Nacional para a Educação Infantil - RCNEI: destaca a necessidade de a Educação Infantil considerar diferentes aspectos que constituem o desenvolvimento integral por considerar que a criança é um ser completo e indivisível;

- Diretrizes Curriculares Nacionais para Educação Básica - DCNEBs: retoma o desenvolvimento integral, ainda que reduza o compromisso da Educação Infantil até cinco anos de idade em decorrência das mudanças na faixa etária de atendimento dessa etapa da educação.

Em relação à Base Nacional Comum Curricular - BNCC, Felipus (2019) destaca que, apesar de limitações, o documento estende a questão do desenvolvimento integral para toda a Educação Básica. A autora justifica sua afirmação pelo trecho no qual se indica que a formação integral " [...] implica compreender a complexidade e a não a linearidade desse desenvolvimento, rompendo com visões reducionistas que privilegiam ou a dimensão intelectual (cognitiva) ou a dimensão afetiva" (BRASIL, 2017, p. 14). A autora, igualmente, lembra que esse documento vincula o desenvolvimento integral ao conceito de educação integral, definindo-a como uma "[...] construção intencional de processos educativos que promovam aprendizagens sintonizadas com as necessidades, as possibilidades e os interesses dos estudantes e, também, com os desafios da sociedade contemporânea" (BRASIL, 2017, p. 14).

Portanto, ainda que existam limitações tanto na definição da legislação como na sua implementação, observa-se a existência de uma preocupação em relação à formação fragmentada. Os próprios direitos de aprendizagem e os campos de experiência indicados na BNCC evidenciam essa preocupação.

Tanto a necessidade de pertinência do ensino como a formação integral motivaram a realização deste estudo bibliográfico, que se apoiou na abordagem qualitativa para analisar fragmentos dos resultados de três pesquisas de mestrado que envolveram a metodo- 
logia do PCE para estímulo da transição do conhecimento descontextualizado às condições que caracterizam a educação complexa. Para essa análise, recorreu-se, do mesmo modo, aos objetivos das três pesquisas com a intenção de evidenciar a ênfase atribuída à metodologia do PCE, como se pode observar nos resultados.

\section{Educação complexa, pertinência e desenvolvi- mento integral na metodologia dos Projetos Cria- tivos Ecoformadores}

Transitar de práticas pedagógicas centradas no paradigma positivista para perspectivas comprometidas com as demandas sociais atuais e atentas às incertezas em relação ao futuro, requisita, minimamente, a implicação de perspectivas educacionais nutridas pela educação complexa. Brevemente contextualizada na sequência, a educação complexa tem por motivação as perspectivas do 'pensamento complexo' e se dinamiza pela 'transdisciplinaridade' e pela 'ecoformação', uma tríade conceitual que motivou a criação e tem legitimado a utilização da metodologia dos Projetos Criativos Ecoformadores (PCE).

A educação complexa tem como papel "[...] propiciar a reflexão e a ação de resgatar a nossa essência e a nossa humanidade, acenando com novas perspectivas de resistência, emancipação e felicidade" (PETRAGLIA, 2008, p. 35). Nesse sentido, supera visões educacionais que, para a autora, cindem a relação não somente entre tempo e história, como também entre ciência e ser humano, acirrando "[...] o individualismo e, com ele, o isolamento do sujeito" (p. 32).

A educação complexa converge com as reflexões de Morin (2009) sobre a necessidade de atenção às relações entre o humano e o universo, orientando as áreas de conhecimento pela condição humana. Nesse processo, vincula os conceitos 'pensamento complexo' e transdisciplinaridade.

O pensamento complexo é considerado "[...] um tipo de pensamento que não separa, mas une e busca as relações existentes entre os diversos aspectos da vida [...]" (PETRAGLIA, 2013, p. 
16). Isso deriva do fato de a complexidade não constituir " [...] um conceito teórico, uma elucubração metafísica, mas um fenômeno, um fato, um evento, uma trama", pois ela compreende a vida, a natureza (SÁ, 2019, p. 21).

Para o autor, uma das teses nodais do pensamento complexo é a religação dos saberes e "[...] portanto, a superação da fragmentação dos conhecimentos sobre o humano, a natureza e a sociedade". Por isso, o conhecimento pertinente é o conhecimento complexo, pois "[...] abarca a vida, abraça o objeto de estudo, o fato e o fenômeno [...]", já que "Não há nada ou coisa ou fato que possa ser compreendido à luz do Pensamento Complexo de forma isolada. Isso porque não há nada isolado no universo" (SÁ, 2019, p. 21).

Esse pensamento é, portanto, capaz de compreender a multidimensionalidade dos fatos, justamente por não se tratar de um pensamento reducionista, mutilado (MORIN, 1998). “[...] Trata-se de um pensamento que integra os diferentes modos de pensar, opondo-se a qualquer mecanismo disjuntivo" (PETRAGLIA, 2013, p. 16).

A transdisciplinaridade, por sua vez, reverbera o que está entre as disciplinas, através e além delas (NICOLESCU, 2014). Portanto, "[...] diz respeito à dinâmica dos diferentes níveis de realidade" (SANTOS, 2004, p. 111), implicando uma maneira complexa de pensar a realidade, nutrida por "[...] uma atitude que envolve curiosidade, reciprocidade, intuição de possíveis relações existentes entre fenômenos, eventos, coisas, processos e que normalmente escapam à observação comum" (MORAES, 2010, p. 11).

O pensamento complexo e a transdisciplinaridade "[...] aparecem como duas formas de pensamento atual, agrupados à busca de uma perspectiva integradora do conhecimento e da realidade como reação a uma visão atomizante e fragmentada" (ESPINOSA MARTINEZ, 2014, p. 46). As possibilidades para a pertinência do ensino se ampliam quando o pensamento complexo e a transdisciplinaridade se articulam às perspectivas da ecoformação, pois ela se caracteriza pelo compromisso com o bem-estar individual, social e ambiental. 
Silva (2008, p. 102) defende o valor da ecoformação, afirmando que o contato formador com as coisas, com os objetos e com a natureza pode ser "[...] formador de outras ligações, em especial das ligações humanas”. Nesse sentido, Suanno (2014) reforça o papel da ecoformação na consolidação de educação comprometida com o planeta e com todos os seus habitantes.

"A ecoformação traz como complementaridade às outras concepções uma maior ênfase nas relações recíprocas pessoa-ambiente [...]" (PINEAU, 2004, p. 522). Em decorrência, no contexto escolar, estimula-se que os estudantes acessem, aprofundem, construam e difundam conhecimentos e soluções em conexão com a sua realidade, condição que, necessariamente, caracteriza a pertinência do ensino.

Para transitar do currículo colonizado e fragmentado à educação complexa, faz-se necessário utilizar metodologias compatíveis com a tríade conceitual aqui abordada. Uma das possibilidades para esse processo se constitui pelos Projetos Criativos Ecoformadores, abreviadamente nomeada como metodologia do PCE. Apesar da existência de outros tipos de projetos, o PCE tem se destacado pelo potencial que oferece para um ensino "[...] ancorado na vida, estimulando que os docentes e estudantes possam ir 'além da reprodução' de conhecimentos e 'além da análise crítica da realidade’ [...]” (ZWIEREWICZ, 2013, p. 166).

Essa metodologia representa um referencial de ensino e de aprendizagem baseado na autonomia, na transformação, na colaboração e na busca por desenvolvimento integral e, por isso, as práticas decorrentes se vinculam às realidades local e global, transcendendo o conhecimento científico por meio do desenvolvimento de atitudes colaborativas, solidárias e conectadas à vida (TORRE; ZWIEREWICZ, 2009). A estrutura do PCE é formada por dez organizadores conceituais, constituindo uma sequência didática que tem, no epítome, a etapa de abertura da prática pedagógica e, na polinização, o seu encerramento (ZWIEREWICZ, 2017).

A proposta tem sido utilizada em Redes Municipais de Ensino de Santa Catarina, Brasil, como as de Massaranduba, Paulo 
Lopes, São Ludgero e Timbó Grande. Também tem sido utilizada no Instituto Federal de Santa Catarina - IFSC, Campus São José, especialmente no Estágio Supervisionado do Curso de Química, no Instituto Crescer, de Itajaí, e no Mestrado Profissional em Educação Básica - PPGEB da Universidade Alto Vale do Rio do Peixe - UNIARP, de Caçador.

Especificamente, no PPGEB, sua utilização tem relação com a concepção pedagógica que norteia o mestrado. Em decorrência, desenvolvem-se pesquisas, avaliando o potencial do PCE na transformação da prática pedagógica em instituições de Educação Básica.

Neste artigo, sistematiza-se parte dos resultados de três pesquisas vinculadas ao referido mestrado. Trata-se de pesquisas com intervenção desenvolvidas por Telegen (2018), Hoffmann (2019) e Oliveira (2020) e aplicadas na Educação Infantil e nos anos inicias e finais do Ensino Fundamental.

\section{Metodologia da pesquisa}

Por se tratar de um estudo cujo objetivo consiste em analisar implicações da metodologia do PCE para transitar da colonização curricular às possibilidades da educação complexa em pesquisas desenvolvidas no PPGEB, optou-se pela pesquisa bibliográfica e pela abordagem qualitativa. Enquanto a pesquisa bibliográfica oferece condições para realização de estudos em pesquisas precedentes, a abordagem qualitativa "[...] corresponde a um espaço mais profundo das relações, dos processos e dos fenômenos que não podem ser reduzidos à operacionalização de variáveis" (MINAYO, 2010, p. 23), atendendo, dessa forma, à intencionalidade deste estudo.

Este estudo foi organizado em três etapas: na primeira, compilaram-se os indicadores elencados por Telegen (2019) com o intuito de avaliar a proximidade de projetos de ensino e de aprendizagem com a metodologia do PCE; na segunda, situaram-se possibilidades para a pertinência do ensino contextualizadas na pesquisa de Hoffmann (2019); e, na terceira, delimitaram-se condições para estímulo ao desenvolvimento integral compiladas na pesquisa 
de Oliveira (2020). Nessas três etapas, também, compilaram-se os objetivos de cada pesquisa, os quais se analisaram com auxílio do software MaxQDA. Isso possibilitou situar conceitos centrais norteadores da elaboração dos objetivos das três pesquisas analisadas.

\section{Resultados e discussão}

As pesquisas analisadas realizaram-se em três escolas vinculadas a três municípios catarinenses. A primeira envolveu uma escola de Ensino Fundamental vinculada à Rede Municipal de Ensino de Macieira; a segunda, uma escola Ensino Fundamental da Rede Municipal de Timbó Grande; e, a terceira, uma instituição de Educação Infantil vinculada à Rede Municipal de Ensino de Caçador.

Destaca-se, igualmente, que os três estudos priorizaram a pesquisa-ação e a abordagem qualitativa. Em relação aos participantes, a de Telegen (2019) envolveu estudantes dos anos finais do Ensino Fundamental; a de Hoffmann (2019), estudantes dos anos iniciais do Ensino Fundamental e uma docente em atuação na turma implicada no estudo; e a de Oliveira (2020) contou com a participação de bebês e de crianças bem pequenas matriculadas na Educação Infantil e parte dos respectivos pais e/ou responsáveis.

Para contextualizar os três estudos, recorre-se a seus objetivos. Dessa forma, situa-se tanto a metodologia do PCE em cada estudo como a intencionalidade de sua implicação.

\section{- Objetivos das pesquisas analisadas}

A pesquisa de Telegen (2019) teve como objetivo analisar a proximidade e/ou distanciamento do Projeto Incentivo à Leitura, desenvolvido na EMEF Professora Cândida Bertotto Zucatti, do município de Macieira, em relação à metodologia do PCE, visando à identificação de indicadores úteis ao aperfeiçoamento da elaboração e do desenvolvimento de novos projetos. Vinculado a esse propósito, elencaram-se os seguintes objetivos específicos: elaborar um projeto de leitura, adaptado ao $9^{\circ}$ no Ensino Fundamental II da EMEF Professora Cândida Bertotto Zucatti, do município de 
Macieira - SC; avaliar o projeto de leitura desenvolvido a partir da perspectiva de estudantes do $9^{\circ}$ ano do Ensino Fundamental; situar, em cada um dos organizadores conceituais do PCE, um indicador que possibilitasse a análise de aproximações e de especificidades dessa metodologia em relação a projeto de leitura desenvolvido; utilizar os indicadores para confronto do projeto de leitura, desenvolvido na EMEF Professora Cândida Bertotto Zucatti, com os conceitos organizadores da metodologia do PCE, visando à análise de aproximações ou diferenças dos dois tipos de projeto.

A pesquisa de Hoffmann (2019) teve como objetivo avaliar a utilização da metodologia do PCE e seus possíveis impactos sobre a pertinência do ensino no $5^{\circ}$ ano do Ensino Fundamental de uma escola pública de Timbó Grande, Santa Catarina. Em relação aos objetivos específicos, propôs-se: conhecer a percepção dos estudantes em relação à escola e às possibilidades de mudanças nas práticas pedagógicas; sistematizar o PCE desenvolvido no $5^{\circ}$ ano do Ensino Fundamental; conhecer a percepção de estudantes e da docente que participaram da intervenção, destacando condições e limitações do PCE para estímulo à pertinência do ensino.

A pesquisa de Oliveira (2020) teve como objetivo geral avaliar o potencial de um PCE articulado aos campos de experiência ao desenvolvimento integral de bebês e de crianças bem pequenas que frequentam o Centro Municipal de Educação Infantil Elmar Pereira Rosa, de Caçador, Santa Catarina. Para tanto, comprometeu-se em: analisar teses e dissertações relacionadas ao 'protagonismo infantil, 'Educação Infantil' e 'desenvolvimento integral', sistematizando suas contribuições à pesquisa atual; apresentar um Projeto Criativo Ecoformador (PCE), elaborado especificamente para a intervenção no lócus de pesquisa; analisar a proximidade do PCE elaborado à proposta de origem dessa metodologia por meio do uso de indicadores elencados por Telegen (2019); sistematizar atividades realizadas durante o PCE proposto, comprometidas com o uso de materiais não estruturados e a exploração de cenários ecoformadores; analisar a percepção de pais e/ou responsáveis sobre as contri- 
buições do PCE desenvolvido para o desenvolvimento integral de bebês e de crianças bem pequenas.

$\mathrm{Na}$ análise, observou-se a frequência de conceitos-chave considerados na elaboração dos objetivos das três pesquisas. Registrados na Figura 1, os conceitos mais frequentes elucidam condições contextuais, pedagógicas, metodológicas e epistemológicas, confirmando que as intervenções propostas nas pesquisas se distanciam de um ensino descontextualizado. Nesse sentido, incluem a tríade conceitual que norteou as pesquisas: complexidade-transdisciplinaridade-ecoformação.

Além disso, observa-se a conexão entre a tríade e os outros conceitos relacionados à educação complexa, tais como a pertinência, sugerindo a intencionalidade de reiterar uma perspectiva integradora do conhecimento e da realidade e que se contrapõe à visão atomizante e fragmentada da educação, conforme defende Espinosa Martinez (2014).

Figura 1 - Conceitos de referência na elaboração dos objetivos das pesquisas

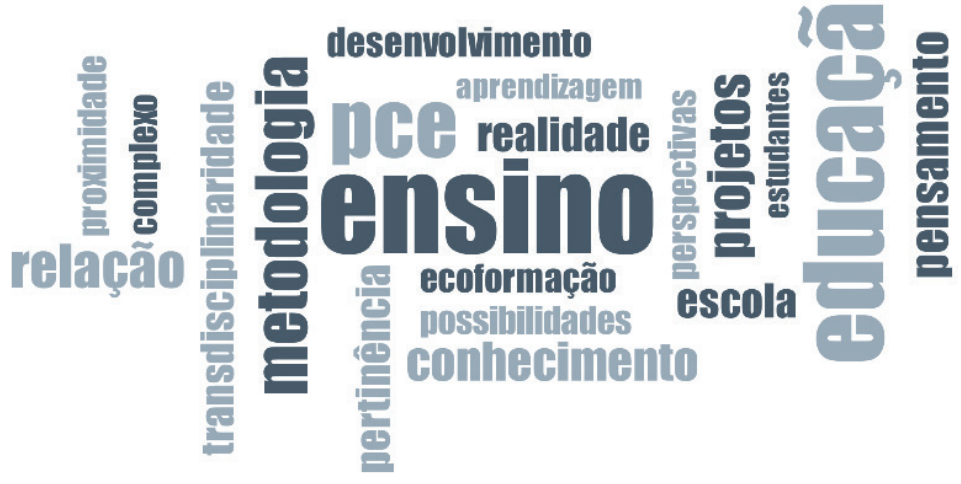

Fonte: Hoffmann (2019), Telegen (2019) e Oliveira (2020). 
Além de situar os 20 conceitos mais frequentes, identificou-se a posição que cada um ocupou. No Gráfico 1, os resultados dessa análise podem ser observados:

Gráfico 1 - Posição dos conceitos mais frequentes

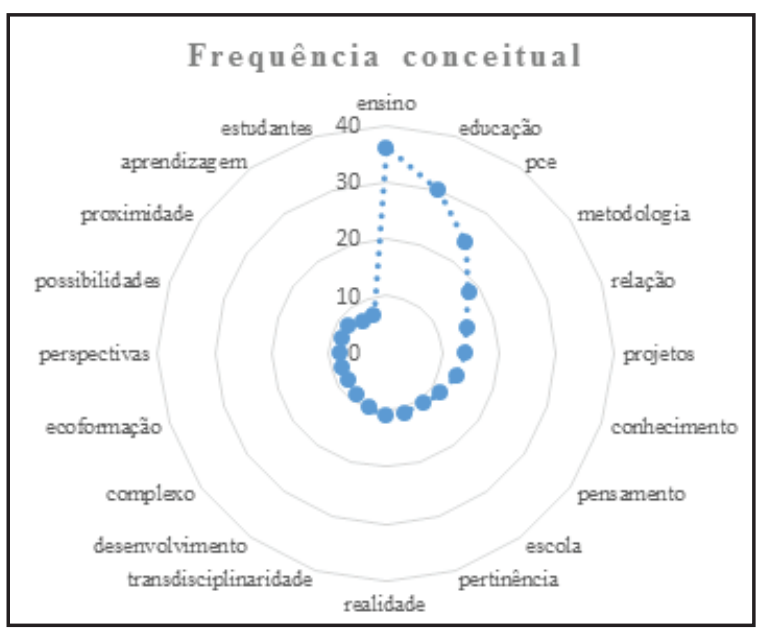

Fonte: Hoffmann (2019), Telegen (2019) e Oliveira (2020).

$\mathrm{O}$ fato de o ensino ser o mais frequente indica o foco das pesquisas. Como implicavam intervenções utilizando a metodologia do PCE, observa-se a relevância da ênfase atribuída aos termos 'realidade' e 'pertinência', denotando um compromisso da intervenção com o estímulo ao pensamento complexo, pois, de acordo com Petraglia (2013), esse busca as relações existentes entre os diversos aspectos da vida.

\section{- Resultados das pesquisas analisadas}

Considerando que o PCE prioriza um ensino ancorado na vida (ZWIEREWICZ, 2013) e que se apoia no pensamento complexo para dinamizar práticas transdisciplinares e ecoformadoras, analisou-se se essa ênfase observada nos objetivos, também, transparece nos resultados, considerando nesse processo: os indicadores para avaliar a proximidade de projetos de ensino e de aprendizagem à metodo- 
logia do PCE; a pertinência do ensino; e o desenvolvimento integral. Nessa análise, parte-se do princípio de que essas três condições confirmam a aproximação com a educação complexa, contribuindo para verificar o real potencial da metodologia do PCE.

\section{- Indicadores para avaliar a proximidade de projetos de ensino e de aprendizagem à metodologia do PCE}

Como indicadores para avaliar a proximidade de projetos de ensino e de aprendizagem à metodologia do PCE, Telegen (2019) indicou dez alternativas. Registradas na Figura 2, os indicadores demonstram o compromisso com a descolonização curricular ao vincular o proposto nos projetos com realidade local e com o estímulo à resolução de situações-problemas com base nas possibilidades oferecidas pela transdisciplinaridade e pela ecoformação.

Figura 2 - Indicadores para avaliar a proximidade de projetos de ensino e de aprendizagem à metodologia do PCE

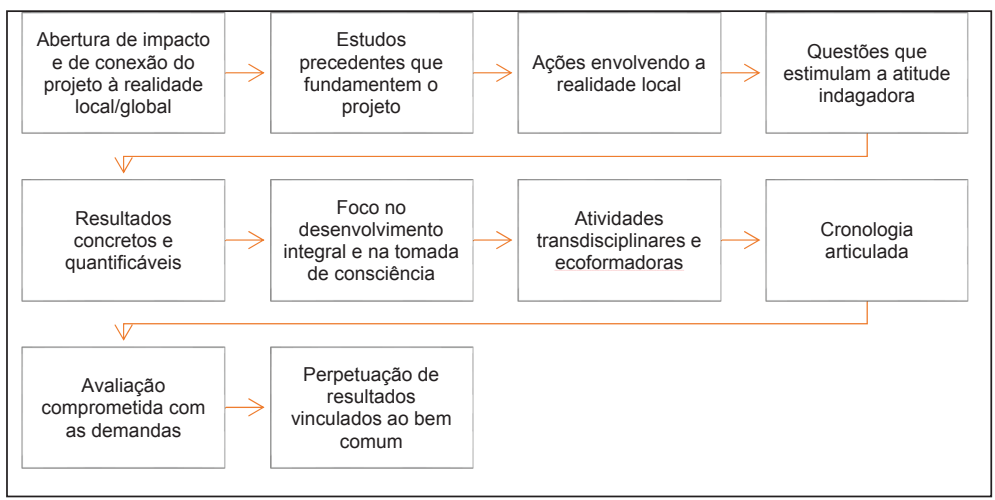

Fonte: Telegen (2019)

Quando faz referência ao desenvolvimento integral, bem como à pesquisa em estudos precedentes, à tomada de consciência e aos resultados dos projetos de ensino e de aprendizagem pautados no bem comum, a pesquisa de Telegen (2019) se aproximou das perspectivas da educação complexa. Dessa forma, sugere que os 
indicadores colaborem para superar perspectivas educacionais os quais, para Petraglia (2008), cindem a relação entre tempo e história e entre ciência e ser humano.

\section{- Pertinência do ensino no desenvolvimento do PCE}

A pesquisa de Hoffmann (2019) envolveu a elaboração de um PCE para o desenvolvimento nos anos iniciais do Ensino Fundamental, vinculando-o à realidade do município de Timbó Grande. Por isso, teve como condições mobilizadoras o cultivo da erva-mate e a roda de chimarrão e a roda de gaiteiros.

Na percepção da docente responsável pelo desenvolvimento do PCE junto aos estudantes de uma das turmas, a proposta acentuou a pertinência do ensino à medida em que se conectou à realidade dos estudantes e de suas famílias. Destacou, como exemplo da articulação realizada entre as demandas locais e os conteúdos curriculares, o acesso à produção da erva-mate, a sua forma de cultivo e a preparação que antecede a sua comercialização.

A percepção dos estudantes coincidiu com a da docente, especialmente quando se afirmou que, em sala de aula, trabalharam-se condições que permeiam as suas realidades, entre elas, os conhecimentos acessados na entrevista realizada com avós, pais e vizinhos, a vivência junto à roda de chimarrão, o contato com a propriedade de cultivo de erva-mate e a distribuição de mudas, a produção textual, envolvendo o que estudaram, a música e as receitas com erva-mate. Além disso, houve destaque sobre o quanto as aulas de campo ofereceram condições para confrontar conhecimentos tradicionais/empíricos aos técnicos/científicos, além de oportunizar o contato com conhecimentos não dominados anteriormente.

\section{- Desenvolvimento integral no uso da metodologia do PCE}

Na pesquisa de Oliveira (2020), a intervenção proposta implicou o desenvolvimento de um PCE comprometido com o desenvolvimento integral, envolvendo bebês e crianças bem peque- 
nas. Nessa proposta, estimulou-se o protagonismo dos envolvidos na tomada de decisões, especialmente, no uso de materiais não estruturados e na construção de cenários ecoformadores.

A intenção do PCE era "[...] transcender a prática pedagógica centrada no professor e trabalhar, sobretudo, a sensibilidade deste para uma aproximação real da criança, compreendendo-a do ponto de vista dela, e não do ponto de vista do adulto" (OLIVEIRA; CRUZ, 2010, p. 6). Nesse sentido, Oliveira (2020) concluiu que, além de possibilitar aos bebês e às crianças bem pequenas novos contatos, novas possibilidades, novas sensações e desafios, cultivou-se a perspectiva ecoformadora, a qual tem, entre seus compromissos, uma formação aberta aos novos desafios que a sociedade atual enfrenta e que demanda o respeito e o cuidado com a vida no e do planeta.

A coleta de dados envolveu os pais e/ou responsáveis, que expressaram sua percepção em relação às contribuições do PCE para o desenvolvimento integral. Entre os aspectos mais desenvolvidos, destacaram a linguagem oral, a autonomia para realizar as tarefas, a criatividade, a coordenação motora, o afeto, a resolução de conflitos e o envolvimento em situações de faz de conta. Essas condições demonstram a implicação de diferentes dimensões que envolvem o desenvolvimento integral.

Como essas dimensões se aproximam aos campos de experiência indicados pela BNCC (BRASIL, 2017), Oliveira (2020) fez uma análise de cada um deles, destacando o posicionamento dos pais e/ ou responsáveis sobre em que aspectos o PCE havia contribuído. Como exemplos, destaca-se que, no campo de experiência, 'o eu, o outro e o nós' evidenciaram as contribuições especialmente para a ampliação das relações interpessoais estabelecidas pelos bebês e pelas crianças bem pequenas e na tomada de decisão, enquanto no campo de experiência 'corpo, gestos e movimentos', destacaram a ampliação da autonomia na hora das refeições e no campo 'traços, sons, cores e formas' o interesse nos materiais riscantes e no uso de diferentes estratégias para explorá-los. 


\section{Considerações finais}

Com a clareza de que transitar de um ensino descontextualizado à educação complexa representa um desafio devido a todas as implicações que demandam desse processo, este estudo priorizou pesquisas que se comprometeram com essa transição. Nesse processo, valeu-se da tríade conceitual - pensamento complexo-transdisciplinaridade-ecoformação - para vincular as especificidades teóricas à metodologia de ensino utilizada na intervenção das três pesquisas analisadas.

Ao ter como base metodológica o PCE, observou-se que as pesquisas trouxeram contribuições para articular o que se estudava em sala de aula à realidade dos estudantes. São exemplos dessa articulação a produção de erva-mate, a exploração de materiais não estruturados e a construção de cenários ecoformadores.

Exemplos como esses denotam a busca pela superação da fragmentação do conhecimento e que desconsidera uma necessidade básica que Baumeister e Leary (1995) definem como 'pertencimento'. Portanto, constituíram formas de reagir àquilo que Espinoza Martinez (2014) considera uma visão atomizante e fragmentada.

$\mathrm{Na}$ mesma direção, destaca-se a contribuição da metodologia do PCE para o desenvolvimento integral. A partir disso, vale enfatizar que, enquanto as práticas pedagógicas valorizam a transmissão de conteúdos predeterminados, comprometendo-se com exclusividade à dimensão intelectual, as pesquisas demonstraram existir possibilidades, tanto na Educação Infantil como no Ensino Fundamental, de estimular diferentes dimensões implicadas no desenvolvimento integral.

Considerando que, para Morin (2015, p. 5), "As soluções existem, proposições inéditas surgem nos quatro cantos do planeta, com frequência em pequena escala, mas sempre com o objetivo de iniciar um verdadeiro movimento de transformação da sociedade", conclui-se este estudo, recuperando alguns dos indicadores elencados por Telegen (2019), por considerá-los fundamentais para tornar possível, ainda que de forma localizada, a educação complexa. 
São eles: conexão do projeto à realidade local/global, questões que estimulam a atitude indagadora, foco no desenvolvimento integral e na tomada de consciência, atividades transdisciplinares e ecoformadoras e perpetuação de resultados vinculados ao bem comum.

\section{Referências}

BAUMEISTER, Roy F. Need-to-belong theory. In: VAN LANGE, Paul A. M.; KRUGLANSKI, Arie W.; HIGGINS, E. Tory (Org.). Handbook of theories of social psychology. Londres: Sage, 2012. p. 121-140.

BAUMEISTER, Roy F.; LEARY, Mark R. The Need to Belong: Desire for Interpersonal Attachments as a Fundamental Human Motivation. Psychological Bulletin, v. 117, n. 3, p. 497-529, 1995. Disponível em: https://pdfs. semanticscholar.org/3dcc/3d262c08f8f4eb8f766ad72f06d580869309.pdf?_ $\mathrm{ga}=2.75756247 .337573953 .1565627548-480277017.1565627548$. Acesso em: 20 maio 2018.

BRASIL. Base Nacional Comum Curricular: Educação é a base. Brasília: MEC, 2017. Disponível em: <http://basenacionalcomum.mec.gov.br/images/BNCC_ publicacao.pdf>. Acesso em: 12 ago 2017.

CAVALCANTE, Rafael Gomes; AQUINO, Alysson Educardo de Carvalho; MELO, Alessandro de. Descolonizar a pedagogia crítica: uma crítica à pedagogia histórico-crítica. MELO, Alessandro et al. (Org.). Perspectivas decoloniales sobre la educación. Guarapuava: Unicentro, 2019, p. 95-138.

DEWALL, C. Nathan; BAUMEISTER, Roy F. Alone but feeling no pain: Effects of social exclusion on physical pain tolerance and pain threshold, affective forecasting, and interpersonal empathy. Journalo Of Personality and Social Psychology, n. 91, v. 1, 2006. Doi: 10.1037/0022-3514.91.1.1.

ESPINOSA MARTÍNEZ, Ana Cecília. Abrir los saberes a la complejidad de la vida: nuevas prácticas transdisciplinarias en la universidad. Puerto Vallarta: CEUArkos, 2014.

FELIPUS, Eliane Scheffmacher. Implicações dos Projetos Criativos Ecoformadores (PCE) no desenvolvimento integral de crianças da Educação Infantil. 2020. Dissertação (Mestrado Profissional em Educação Básica) - Universidade Alto Vale do Rio do Peixe, Caçador, 2020.

GASTAL, Camila Azevedo; PILATI, Ronaldo, Escala de Necessidade de Pertencimento: Adaptação e Evidências de Validade. Psico-USF, v. 21, n. 2, maio-a- 
go, 2016, pp. 285-292, 2016. Disponível em: <http://www.redalyc.org/articulo. oa?id=401047459007. Acesso em: 12 dez. 2017.

HOFFMANN, E. A pertinência do ensino no uso da metodologia dos Projetos Criativos Ecoformadores (PCE) no Ensino Fundamental. 2019. Dissertação (Mestrado Profissional em Educação Básica) - Universidade Alto Vale do Rio do Peixe, Caçador, 2019.

MINAYO, Maria Cecília de Souza. Pesquisa social: teoria, método e criatividade. 21. ed. Petrópolis: Vozes, 2010.

MORAES, Maria Cândida. Transdisciplinaridade e educação. Rizoma Freireano, Sevilha, v. 6., p. 1-18, 2010. Disponível em: http:/ /www.rizoma-freireano.org/ transdisciplinaridade-e-educacao--maria-candida-moraes. Acesso em: 20 maio 2019 .

MORIN, Edgar. Ensinar a viver: manifesto para mudar a educação. Tradução de Edgard de Assis Carvalho e Mariza Perassi Bosco. Porto Alegre: Sulina, 2015.

MORIN, Edgar. A cabeça bem-cheia: repensar a reforma, reformar o pensamento. Tradução de Eloá Jacobina. 16. ed. Rio de Janeiro: Bertrand Brasil, 2009.

NICOLESCU, Basarab. Transdisciplinariedad: pasado, presente y futuro. In: ESPINOSA MARTINEZ, Ana Cecilia; GALVANI, Pascal (Org.). Transdisciplinariedad y formación universitária: teorias y prácticas emergentes. Puerto Vallarta: CEUArkos, 2014. p. 45-90.

OLIVEIRA, Beatriz Alves de. Cenários ecoformadores e campos de experiência: contribuições de um Projeto Criativo Ecoformador para o desenvolvimento integral de bebês e crianças bem pequenas. 2020. Dissertação (Mestrado Profissional em Educação Básica) - Universidade Alto Vale do Rio do Peixe, Caçador, 2020.

OLIVEIRA, Zilda de Moraes; CRUZ, Ise Vera. O Currículo na Educação Infantil: o que propõem as novas diretrizes nacionais? In: SEMINÁRIO NACIONAL CURRÍCULO EM MOVIMENTO: perspectivas atuais, I, Belo Horizonte. Anais eletrônicos... Belo Horizonte: MEC, 2010.

PAIVA, Raquel. O espírito comum: comunidade, mídia e globalismo. Rio de Janeiro: Mauad, 2000.

PETRAGLIA, Izabel. Educação complexa para uma nova política de civilização. Educar, Curitiba, v. 32, p. 29-41, 2008.

PETRAGLIA, Izabel. Pensamento complexo e educação. São Paulo: Livraria da Física, 2013. 
PINEAU, Gaston. Écoformation: rapport du GREF. Tours: GREF, 2004.

RIVAS FLORES, José Ignacio. Re-instituyendo la investigación como transformadora: descolonizar la investigación educativa. MELO, Alessandro et al. (Org.). Perspectivas decoloniales sobre la educación. Guarapuava: Unicentro, 2019, p. 23-60.

SÁ, Ricardo Antunes. Contribuições teórico-metodológicas do pensamento complexo para a construção de uma pedagogia complexa. In: SÁ, Ricardo Antunes; BEHRENS, Marilda Aparecida (Org.). Teoria da complexidade: contribuições epistemológicas para uma pedagogia complexa. Curitiba: Appris, 2019. p. 17-64.

SANTOS, Akiko. Didática sob a ótica do pensamento complexo. Porto Alegre: Sulina, 2004.

SILVA, Ana Tereza Reis da. Ecoformação: reflexões para uma pedagogia ambiental, a partir de Rousseau, Morin e Pineau. Desenvolvimento e Meio Ambiente, Curitiba, n. 18, p.95-104, jul/dez, 2008. Disponível em: https://pdfs.semanticscholar.org/26bc/e1874dd2c6097f764584f1d86cee443f3e51.pdf. Acesso em: 17 jan. 2020.

SOUSA, Mauro Wilton de. O pertencimento ao comum mediático: a identidade em tempos de transição. Significação, n. 34, 2010. p. 31-52. Disponível em: http://www3.usp.br/significacao/pdf/Significacao34_2\%20Mauro\%20Wilton $\% 20$ de \%20Sousa.pdf. Acesso em: 08 ago. 2019.

SUANNO, João Henrique. Ecoformação, Transdisciplinaridade e Criatividade: a escola e a formação do cidadão do século XXI. In: MORAES, Maria Cândida; SUANO, João Henrique. O pensar complexo na educação: sustentabilidade, transdisciplinaridade e criatividade. Rio de Janeiro: Wak, 2014. p. 171-182.

TELEGEN, Nadir Zimmer. Da decodificação ao potencial transformador da leitura: indicadores para aproximação de projetos de ensino à metodologia dos Projetos Criativos Ecoformadores (PCE). 2019. Dissertação (Mestrado Profissional em Educação Básica) - Universidade Alto Vale do Rio do Peixe, Caçador, 2019.

TORRE, Saturnino; ZWIEREWICZ, Marlene. Projetos Criativos Ecoformadores. In: ZWIEREWICZ, Marlene; TORRE, Saturnino de la (Org.). Uma escola para o século XXI: escolas criativas e resiliência na educação. Florianópolis: Insular, 2009. p. 153-176.

ZWIEREWICZ, Marlene. Apresentação. In: ZWIEREWICZ, Marlene (Org.). Criatividade e inovação no Ensino Superior: experiências latino-americanas em foco. Blumenau: Nova Letra, 2013. p. 9-16. 